\title{
Demographic Profiles of Animal Bite Cases at a Dedicated Anti-Rabies Hospital in Dhaka City of Bangladesh
}

\author{
Md. Abdullah Yusuf', Tanzina Jahan², AFM Arshedi Sattar³, Sazzad Bin Shahid ${ }^{4}$, \\ Nusrat Sultana ${ }^{5}$, AKM Shamsuzzaman ${ }^{6}$
}

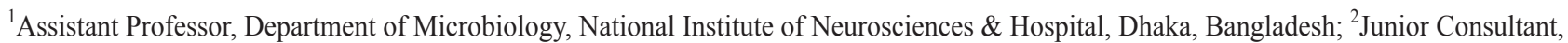
Department of Pathology, Infectious Disease Hospital, Dhaka, Bangladesh; ${ }^{3}$ Associate Professor, Department of Microbiology, National Institute of Neurosciences \& Hospital, Dhaka, Bangladesh; ${ }^{4}$ Associate Professor, Departmentof Microbiology, Dhaka Medical College, Dhaka, Bangladesh; ${ }^{5}$ Assistant Professor, Department of Virology, Dhaka Medical College, Dhaka, Bangladesh; ${ }^{6}$ Director\& Professor of Microbiology, National Institute of Laboratory Medicine \& Referral Centre, Dhaka, Bangladesh
\end{abstract}

[Received: 12 April 2020; Accepted: 20 May 2020; Published: 1 July 2020]

\begin{abstract}
Background: Animal bite management are very crucial part in the post prophylaxis treatment. Objective: The purpose of the present study was to see the demographic profile of animal bite cases at a dedicated anti-rabies hospital. Methodology: This retrospective chart review based on secondary data received from animal bite register was conducted in the Department of Microbiology at National Institute of Neurosciences \& Hospital, Dhaka, Bangladesh from January 2014 to December 2015 for a period of two years. All relevant data were noted from the registered record. Result: A total number of 17688 cases were collected from the register log book of animal bite. The mean age with standard deviation was $24.42 \pm 17.22$ with the range of 1 to 99 years. The ratio between male and female was 2.33:1. The most common animal bite was dog bite which was $13574(76.7 \%)$ cases followed by cat, monkey, fox and weasel bite which were $3667(20.7 \%)$ cases, $163(0.9 \%)$ cases, $39(0.2 \%)$ cases and $22(0.1 \%)$ cases respectively. Lower extremity was the most site of bite by the animals which was $12936(73.1 \%)$ cases followed by upper extremity, waist, head \& neck, face and trunk which were $3592(20.3 \%)$ cases, $428(2.4 \%)$ cases, $155(0.9 \%)$ cases, $116(0.7 \%)$ and $114(0.6 \%)$ cases respectively. The most common category of bite was category II which was $11800(66.7 \%)$ cases. Conclusion: In conclusion male young adult person bite by dog with category II are the most common victims of animal bites seeking for treatment. [Journal of National Institute of Neurosciences Bangladesh, July 2020;6(2): 135-139]
\end{abstract}

Keywords: Demographic Profiles; Animal Bites; Compliance; Intradermal Rabies Vaccine; Anti-Rabies Hospital

Correspondence: Dr. Md. Abdullah Yusuf, Assistant Professor, Department of Microbiology, National Institute of Neurosciences \& Hospital, Sher-E-Bangla Nagar, Agargaon, Dhaka, Bangladesh; Email: ayusuf75@yahoo.com; Cell no.: +8801817565830

Conflict of interest: The principal author has got honorarium from the project for the data entry, statistical analysis and for report writing. There is no biasness during the writing and analyzing of the data.

Funding agency: This research project was funded by Communicable Disease Control, Directorate General of Health Services, Ministry of Health and Family Welfare, Dhaka, Bangladesh for the collection of the data from the record.

Contribution to authors: Yusuf MA, Jahan T, Shamsuzzaman AKM, contributed from the protocol preparation, data collection up to report writing. Manuscript writing was performed by Yusuf MA; Sattar AFMA, Shahid SB, Sultana N have corrected and have revised the manuscript.

How to cite this article:Yusuf MA, Jahan T, Sattar AFMA, Shahid SB, Sultana N, Shamsuzzaman AKM. Demographic Profiles of Animal Bite Cases at a Dedicated Anti-Rabies Hospital in Dhaka City of Bangladesh. J Natl Inst Neurosci Bangladesh, 2020;6(2): $135-139$

Copyright: (C2020. Yusuf et al. Published by Journal of National Institute of Neurosciences Bangladesh. This article is published under the Creative Commons CC BY-NC License (https://creativecommons.org/licenses/by-nc/4.0/). This license permits use, distribution and reproduction in any medium, provided the original work is properly cited, and is not used for commercial purposes.

\section{Introduction}

Rabies is a viral zoonotic disease caused by infection with the rabies lyssavirus which is highly infectious and it has almost $100 \%$ case fatality ${ }^{1}$. This disease transmits to humanwhen a rabid animal suffering from rabies bites or licks human beings. The overall data on animal bites is very scanty and unreliable in Bangladesh dueto lack of quality surveillance, reporting system as well as misconception of general people about treatment. In addition, a common problem with rabies reporting has been that suspect case reports are not submitted from district levels to the central authorities, as a result of the 
lack of an organized reporting system and currently this has been overcome ${ }^{2}$. Furthermore, there are poor levels of reporting from private sector hospitals and clinics on the periphery of the health system.

Thus the actual scenario is even worse than estimated burden. There is no treatment or cure so far for rabies. However, prevention in the form of post exposure prophylaxis (PEP) is the only intervention ${ }^{3}$. It has been estimated that if timely post exposure prophylaxis is not given, then every year 3.27 lakh people would die just in Asia and Africa ${ }^{4}$. The implications for the dynamics of rabies are likely to be profound, resulting in an increase in the size of rabies outbreaks, the probability of disease persistence, and the likelihood of dog-to-human transmission. More generally, in the developing countries, patients with rabies may not report to health centres due to the known futility of treatment, the preference for consulting practitioners outside mainstream medicine, the costs of travel to hospitals and the wrong perception in some areas. In addition, there are few funds for conducting either dog rabies incidence surveys or follow-up studies of treated patients, and laboratory confirmation of the rabid status of suspect dogs is lacking, as a result of financial and logistic constraints.

In the neighborhood country, approximately 20,000 of an estimated global annual 55,000 rabies deaths occur In India and three-quarters of these deaths occur in rural areas $^{6}$. In addition to causing pain, injury and mental trauma, dogs are the source of rabies in nearly $100.0 \%$ cases $^{7}$. As per the policy of the Government of Bangladesh, there should be free anti rabies vaccine for all the dog bite patients from the level of primary health centers under the controlled cold chain.Knowledge about post exposure prophylaxis is essential in the community to seek vaccination after animal bite. Considering this background, the present study was undertaken to describe the epidemiological characteristics of animal bite victims attending emergency department at Infectious Disease Hospital in Dhaka city.

\section{Methodology}

This was a retrospective study based on secondary data which were received from animal bites register in the Infectious Disease Hospital, Dhaka, Bangladesh from January 2014 to December 2015 for a period of two years. This study was conducted in the Department of Microbiology at National Institute of Neurosciences \& Hospital, Dhaka, Bangladesh. All the relevant data of the patients like age, sex, name of the animal, site of bite in the body and the date of the post-exposure anti-rabies vaccines who were attended in the emergency department at Infectious Disease Hospital in Dhaka city of Bangladesh for the management for animal bite retrieved and extracted from the record book. The Infectious Disease Hospital was located in Dhaka city of Bangladesh which was a dedicated hospital for pre- and post-exposure prophylaxis of rabies. People of different corners of the country were attended in this hospital. All the services like indoor, outdoor and emergency were available. The patients with missing data in the registered book were excluded from this study. It was also reviewed the admission and discharge books at the medical and emergency departments of the hospital to identify records of all cases of rabies reported during the period. The animal bites were categorized according to the WHO classification into category I, II and III. Category I was defined as touching or feeding animals, animal licks on intact skin (no exposure). Category II was the nibbling of uncovered skin, minor scratches or abrasions without bleeding (exposure). Category III was the single or multiple transdermal bites or scratches, contamination of mucous membrane or broken skin with saliva from animal licks, exposures due to direct contact with bats (severe exposure).Prior of the study the study protocol was approved by the local Ethics Review committee. Personal identifiers were omitted in order to maintain confidentiality and anonymity.The statistical analysis was performed by Stata version 16.0. The qualitative data were expressed as mean and percent. The quantitative data were expressed as mean with standard deviation. The Chi-square test was performed between qualitative data to see the level of significance. All the analysis were in 2-tailed. $\mathrm{P}$ value less than 0.05 was taken as significant.

\section{Results}

A total number of 17688 cases were collected from the register log book of animal bite. The most common age group was less than 20 years which was $8654(48.9 \%)$ cases followed by 20 to 40 years, 40 to 60 years which was 5947(33.6\%) cases and 2613(14.8\%) cases respectively. However, more than 60 years age group was found in $474(2.7 \%)$ cases. The mean age with standard deviation was $24.42 \pm 17.22$ with the range of 1 to 99 years (Table 1 ).

Male was predominant than female which was $12378(70.0 \%)$ cases and 5310(30.0\%) cases respectively. The ratio between male and female was 2.33:1 (Table 2). 
Table 1: Distribution of Age group $(n=17688)$

\begin{tabular}{lcc}
\hline Age Group & Frequency & Percent \\
\hline Less than 20 Years & 8654 & 48.9 \\
20 to 40 Years & 5947 & 33.6 \\
40 to 60 Years & 2613 & 14.8 \\
More Than 60 Years & 474 & 2.7 \\
Total & $\mathbf{1 7 6 8 8}$ & $\mathbf{1 0 0 . 0}$ \\
Mean \pm SD & $24.42 \pm 17.22(1$ to 99) \\
\hline
\end{tabular}

Table 2: Gender Distribution of Study Population $(\mathrm{n}=17688)$

\begin{tabular}{lcc}
\hline Gender & Frequency & Percent \\
\hline Male & 12378 & 70.0 \\
Female & 5310 & 30.0 \\
Total & $\mathbf{1 7 6 8 8}$ & $\mathbf{1 0 0 . 0}$ \\
\hline
\end{tabular}

The most common animal bite was dog bite which was $13574(76.7 \%)$ cases followed by cat, monkey, fox and weasel bite which were $3667(20.7 \%)$ cases, $163(0.9 \%)$ cases, $39(0.2 \%)$ cases and $22(0.1 \%)$ cases respectively. There were some others animal bite as well which was $218(1.2 \%)$ cases (Table 3 ).

Table 3: Distribution of Different Animals Bites $(\mathrm{n}=17683)$

\begin{tabular}{lcc}
\hline Animals Bites & Frequency & Percent \\
\hline Dog Bite & 13574 & 76.7 \\
Cat Bite & 3667 & 20.7 \\
Monkey Bite & 163 & 0.9 \\
Fox Bite & 39 & 0.2 \\
Weasel Bite & 22 & 0.1 \\
Others & 218 & 1.2 \\
Total & $\mathbf{1 7 6 8 3}$ & $\mathbf{1 0 0 . 0}$ \\
\hline
\end{tabular}

Animals were bite in the different parts of the body. Lower extremity was the most site of bite by the animals which was $12936(73.1 \%)$ cases followed by upper extremity, waist, head \& neck, face and trunk which were $3592(20.3 \%)$ cases, $428(2.4 \%)$ cases, $155(0.9 \%)$ cases, $116(0.7 \%)$ and $114(0.6 \%)$ cases

Table 4: Site of Bite in the Different Parts of Body $(\mathrm{n}=17683)$

\begin{tabular}{lcc}
\hline Parts of Body & Frequency & Percent \\
\hline Lower Extremity & 12936 & 73.1 \\
Upper Extremity & 3592 & 20.3 \\
Face & 116 & 0.7 \\
Trunk & 114 & 0.6 \\
Head \& Neck & 155 & 0.9 \\
Waist & 428 & 2.4 \\
Others & 342 & 1.9 \\
Total & $\mathbf{1 7 6 8 3}$ & $\mathbf{1 0 0 . 0}$ \\
\hline
\end{tabular}

respectively. There were also bites in some other parts of the body which was 342(1.9\%) cases (Table 4).

Table 5: Different Categories of Bite $(n=17683)$

$\begin{array}{lcc}\text { Category } & \text { Frequency } & \text { Percent } \\ \text { Category I } & 2027 & 11.5 \\ \text { Category II } & 11800 & 66.7 \\ \text { Category III } & 3856 & 21.8 \\ \text { Total } & \mathbf{1 7 6 8 3} & \mathbf{1 0 0 . 0}\end{array}$

There were several categories of bites. The most common category of bite was category II which was $11800(66.7 \%)$ cases followed by category III and category I which were $3856(21.8 \%)$ cases and $2027(11.5 \%$ ) cases respectively (Table 5).

\section{Discussion}

Rabies is endemic in Bangladesh with high public health significance and ranked third highest among rabies-endemic countries for human rabies deaths ${ }^{8}$. In Bangladesh, an estimated 200000 animal bite cases with more than 2000 human rabies deaths are reported annually ${ }^{9}$. Most of the victims are children below 15 years old coming from poor rural communities ${ }^{8-9}$. The main referral centre for rabies patients in Bangladesh is the Infectious Disease Hospital (IDH) located in Dhaka City which provides free treatment to 350 to 450 dog bite victims daily ${ }^{8}$. There are 65 rabies prevention and control centres at the district level which provide a free anti-rabies vaccine (ARV) and treatment to dog bite victims ${ }^{10}$. In a passive surveillance study in Bangladesh (2010-2012), 3425 rabies deaths in domestic animal populations (cattle: 2845; goats: 547; sheep: 13) were reported $^{11}$. However, this surveillance did not capture rabies cases in dogs, and reliable rabies data in the country are scarce. No large-scale dog vaccination campaigns have taken place in Bangladesh for several years and rural dog populations are generally not vaccinated against rabies through private means ${ }^{10}$. Currently this has been started in pilot project basis in selected district of Bangladesh.

Considering the public health importance of rabies, the government of Bangladesh has taken various initiatives to eliminate rabies with four strategies implemented like advocacy, communication and social mobilization (ACSM), modern treatment for dog bite, mass dog vaccination $(\mathrm{MDV})$ and dog population management ${ }^{12}$. However, the success of this programme will depend on people's awareness of rabies and their attitude towards dogs and informed health care seeking behaviour following dog bites ${ }^{13}$. Community 
knowledge, attitudes and practices are important for the prevention and control of rabies both in humans and animals ${ }^{14}$.

In this study a total number of 17688 cases were collected from the register log book of animal bite. The most common age group was less than 20 years which was $8654(48.9 \%)$ cases followed by 20 to 40 years, 40 to 60 years which was $5947(33.6 \%)$ cases and 2613(14.8\%) cases respectively. However, more than 60 years age group was found in $474(2.7 \%)$ cases. The mean age with standard deviation was $24.42 \pm 17.22$ with the range of 1 to 99 years. From this review of records of largest infectious disease hospital in Bangladesh it is clear that young adult is the most commonly victims of the animal bites. Less than 20 years age group are the main victims. The reason may be the nature of the response towards the animals. Majority time they try to hit the animal without any reason which might cause the incidence. However, it is also focused that the victim may be any age group.

In this study the most common animal bite was dog bite which was $13574(76.7 \%)$ cases followed by cat, monkey, fox and weasel bite which were 3667(20.7\%) cases, $163(0.9 \%)$ cases, $39(0.2 \%)$ cases and $22(0.1 \%)$ cases respectively. There were some others animal bite as well which was $218(1.2 \%)$ cases. Rabies is a highly fatal, zoonotic disease that causes severe destruction of the central nervous system of all warm-blooded animals. Typically, humans acquire rabies following the bite of a rabid animal. Domestic dogs (Canisfamiliaris) play a key role in the transmission of rabies to humans. About $85 \%$ to $95 \%$ of human rabies cases in China; and 94\% to $98 \%$, in India and Pakistan are ascribed to dog bites ${ }^{15}$.

The vast majority (99\%) of human deaths arising from rabies occur in the tropical developing world ${ }^{17}$.About 24,000 to 70,000 people are estimated to die of rabies each year in Africa and Asia ${ }^{11}$. Most of the incidences of human rabies occur in rural areas. It has been proposed that this is due to a number of reasons, including low vaccination coverage of dogs as a result of inadequate awareness of the problem, as well as inability to finance the costs of vaccination, poor management of dogs, in particular the free movement of dogs, which increases their risk of contracting rabies from wildlife and although effective and economical control measures are available, rabies remains a neglected disease in terms of policy formulations throughout most of the developing countries ${ }^{13}$. The lack or low level of political commitment to control rabies is perhaps due to lack of accurate data about rabies to clearly show its impact on public health and socioeconomic affairs.

The human population boom in Bangladesh appears to correlate well with the increase in the number of domestic $\operatorname{dog} \mathrm{s}^{12}$. Nevertheless, by conservative estimates, the prevalence of human rabies is considered to be under-reported. The under-reporting is largely attributed to poor surveillance systems and/ or people's tendency not to report human and animal cases of rabies. Sole reliance on clinical diagnosis (in animals and/ or humans) is also downgrading the reliability of rabies-surveillance systems. Thus there has been poor planning resulting in poor availability and inappropriate administration of post-exposure prophylaxis (PEP), as well as delays in its administration ${ }^{10}$.

Animals were bite in the different parts of the body. Lower extremity was the most site of bite by the animals which was 12936(73.1\%) cases followed by upper extremity, waist, head \& neck, face and trunk which were $3592(20.3 \%)$ cases, $428(2.4 \%)$ cases, $155(0.9 \%)$ cases, $116(0.7 \%)$ and $114(0.6 \%)$ cases respectively. There were also bites in some other parts of the body which was 342(1.9\%) cases. If used keenly, reports of animal-bite injuries would aid in estimating area- or region-specific disease burden, thus enabling giving priority to improved rabies surveillance and control. Reports of animal-bite victims in the hospitals and health centers are examples of resources for such information?

\section{Conclusion}

In conclusion male is predominant than female suffered from animal bite. In this study young adult person are more common age group though all age group are also found to be affected by animal bite. The most common animal is the dog followed by cat and monkey. Furthermore, category II is the most common type of injury among the victims facing after the animal bites. Therefore proper management should be implemented to tackle these fatal disease.

\section{References}

1. World Health Organization (WHO). News Fact sheets. Key facts. Animal bites. WHO; 2018. Available at: http://www.who.int/ mediacentre/factsheets/fs373/en/. Accessed on 10 July 2019.

2. Nelima KA. Vertebrate Animal Bite/Scratch Injuries and Management among Patients Reporting at Kakamega Provincial General Hospital(Doctoral dissertation, Applied Epidemiology, JKUAT).

3. World Health Organization. Rabies Fact Sheet. World Health 
Organization; 2017 Available at: http://www.who.int/mediacentre/ factsheets/fs099/en/. Accessed on 10 July 2019.

4. Gowda P, Metri SS, Sundar M. Study of demographic profile of animal bite cases and management practices in a dedicated anti rabies clinic of a tertiary care hospital, Hassan, Karnataka. International journal of community medicine and public health (Gujarat). 2019;6(11):4816-21.

5. Sudarshan MK, Mahendra BJ, Madhusudana SN, Narayana DA, Rahman A, Rao NS, X-Meslin F, Lobo D, Ravikumar K. An epidemiological study of animal bites in India: results of a WHO sponsored national multi-centric rabies survey. Journal of Communicable Diseases. 2006;38(1):32.

6. Kularatne SA, Ralapanawa DM, Weerakoon K, Bokalamulla UK, Abagaspitiya N. Pattern of animal bites and post exposure prophylaxis in rabies: A five year study in a tertiary care unit in Sri Lanka. BMC infectious diseases. 2015;16(1):62.

7. Chaudhary N, Brar MS, Mishra S, Randhawa A. Descriptive profile of patients attending antirabies clinic: a hospital based study of animal bite cases in Patiala. International Journal of Community Medicine and Public Health. 2020;7(6):2326.

8. Kole AK, Roy R, Kole DC. Human rabies in India: a problem needing more attention. Bull World Health Organisation. 2014;92(4):230

9. Pavithra R, Viveki RG, Halappanavar AB. Socio Demographic Profile and Management Practices of Animal Bite Cases Attending Anti Rabies Clinic in a Tertiary Care Centre in North Karnataka. IJAR. 2015;5(1):371-.

10. Samreen S, Ashraf A, Hassan M, Khan SS. Profile of Animal Bite Cases at Anti-Rabies Clinic of Tertiary Care Hospital: A Record Based Study. Journal of Medical Science and Clinical Research 2019;7(4):893-96
11. Singh AD, Rochwani R. Sociodemographic profile and treatment seeking behaviour of animal bite patients attending the anti-rabies clinic at Patiala, Punjab. International journal of community medicine and public health (Gujarat). 2020;7(6):2287-90.

12. Sreenivas NS, Sakranaik S, Sobagiah RT, Kumar A. An epidemiology of animal bite cases attending tertiary care centre of Bangalore Medical College and Research Institute, Bengaluru: a retrospective study. Int $\mathrm{J}$ Community Med Public Health. 2017;4(7):2538-42.

13. Marathe N, Kumar S. Epidemiological study of animal bite victims in Central India: a cross sectional institutional study. International journal of community medicine and public health (Gujarat). 2016;3(1):78-82.

14. Parmar D, Vora D, Rathod P, Narlawar U. Epidemiological profile of animal bite cases attending Anti rabies clinic and pretreatment practices adopted by them following animal bite: A cross-sectional study. Int J Med Health Res. 2016;2(4):11-3.

15. Kulkarni P, Marulappa VG, Manjunath R. Clinico-epidemiological study of human rabies cases attending epidemic disease hospital Mysore city, Karnataka, India. Int J Community Med Public Health. 2017;4(8):2825-9

16. Vishwanath G, Rajderkar S, Sangrulkar T, Sharma S, Gajbhiye $\mathrm{R}$. Animal bite cases in western Maharashtra, India: a retrospective study 2010-2015. International Journal of Community Medicine And Public Health. 2018;5(4):1610-2.

17. Acharya R, Sethia R, Sharma G, Meena R. An analysis of animal bite cases attending anti-rabies clinic attached to tertiary care centre, Bikaner, Rajasthan, India. Int J Comm Med Public Health. 2016:1945-8. 